\title{
Value of endobronchial ultrasound-guided transbronchial needle aspiration (EBUS-TBNA) in the diagnosis of lung and mediastinal lesions
}

\author{
(D)A Austo Carbonari \\ (iD)Lucio Rossini ${ }^{1}$ \\ (iD) Fabio Marioni ${ }^{1}$ \\ (iD) Marco Camunha ${ }^{1}$ \\ (iDMauro Saieg ${ }^{2}$ \\ (D) Fabiola Bernardi² \\ (iD) Fernando Maluf ${ }^{3}$ \\ (iD) Marcio Botter ${ }^{4}$ \\ (i) Vicente Dorgan ${ }^{4}$ \\ (iD) Roberto Saad ${ }^{4}$
}

1. Hospital Santa Casa de São Paulo - Departamento de Endoscopia e Centro Franco Brasileiro de Ecoendoscopia (CFBEUS), São Paulo, SP, Brasil. 2. Hospital Santa Casa de São Paulo - Departamento de Patologia, São Paulo, SP, Brasil. 3. Hospital Santa Casa de São Paulo - Departamento de Oncologia, São Paulo, SP, Brasil. 4. Hospital Santa Casa de São Paulo - Departamento de Cirurgia Torácica, São Paulo, SP, Brasil.

http://dx.doi.org/10.1590/1806-9282.66.9.1210

\section{SUMMARY}

OBJECTIVE: To evaluate the value of EBUS-TBNA in the diagnosis of lung and mediastinal lesions.

METHODS: Prospective cohort study that included 52 patients during a 2-year period (2016 to 2018) who underwent EBUS-TBNA.

RESULTS: Among the 52 individuals submitted to the procedure, 22 (42.31\%) patients were diagnosed with locally advanced lung cancer (N2 or N3 lymph node involvement). EBUS-TBNA confirmed the diagnosis of metastases from other extrathoracic tumors in the mediastinum or lung in 5 patients (9.61\%), confirmed small cell lung cancer in 3 patients (5.76\%), mediastinal sarcoidosis in 1 patient (1.92\%), and reactive mediastinal lymph node in 8 patients (15.38\%); insufficient results were found for 3 patients (5.76\%). Based on these results, EBUS-TBNA avoided further subsequent surgical procedures in 39 of 52 patients (75\%). The sensitivity, specificity, positive predictive value, negative predictive value, and accuracy were $86 \%, 100 \%, 100 \%, 77 \%$, and $90 \%$, respectively. No major complications were observed.

CONCLUSIONS: EBUS-TBNA is a safe, effective, and valuable method. This technique can significantly reduce the rate of subsequent surgical procedures required for the diagnosis of lung and mediastinal lesions.

KEYWORDS: Lung neoplasms. Lymph nodes. Biopsy, needle/methods. Mediastinal diseases/diagnosis. Endoscopic ultrasound-guided fine-needle aspiration. Image-guided biopsy. 


\section{INTRODUCTION}

Various thoracic diseases, benign or malignant, include lung and mediastinal lesions, with varied etiologies and different evolutions. Given this wide variety of diseases, it is critical to make a definitive histopathological diagnosis so that patients can be offered the most appropriate and effective treatment. Different diagnostic modalities are available, including bronchoscopy with transbronchial biopsy, computed tomography-guided fine-needle aspiration, mediastinoscopy, thoracoscopy, endoscopic ultrasound-guided fine-needle aspiration (EUS-FNA), and, more recently, endobronchial ultrasound-guided transbronchial needle aspiration (EBUS-TBNA). Each of these procedures has specific indications, risks and benefits, and different statistical results, availability, and costs.

EBUS-TBNA is considered a minimally invasive procedure, performed under sedation on an outpatient basis. The method allows real-time evaluation of lung and mediastinal lesions, located adjacent to the main airways. In addition to lung cancers, EBUS-TBNA plays an important role in the diagnosis of benign and malignant mediastinal lymph nodes, with excellent results and low complication rates ${ }^{1}$. The method also allows diagnosing pulmonary and mediastinal inflammatory and infectious diseases, including sarcoidosis $^{2,3}$ and tuberculosis ${ }^{4,5}$. In addition, EBUS-TBNA can be useful for diagnosing malignant mediastinal lesions such as lymphomas ${ }^{6}$ and mediastinal metastases of extrathoracic tumors ${ }^{7}$.

The aim of this study is to evaluate the value of EBUS-TBNA in the diagnosis of lung and mediastinal lesions.

\section{METHODS}

This is a clinical and prospective observational study that included 52 patients who underwent EBUS-TBNA, over a period of 2 years (December 2016 - December 2018). All patients agreed to participate in the study and signed an informed consent form. The study was approved by the Ethics Committee on Human Research of Santa Casa de São Paulo under number 1,756,905.

\section{Inclusion criteria}

Patients who had pulmonary or mediastinal lesions, previously identified by chest CT, larger than $5 \mathrm{~mm}$ in size, and considered potentially accessible by EBUS-TBNA.

\section{Exclusion criteria}

Patients who had normal anatomical findings or vascular interposition that did not indicate nor allowed needle aspiration.

\section{Procedures}

EBUS-TBNA was performed on an outpatient basis under conscious or deep sedation and local anesthesia using a flexible convex ultrasound bronchoscope (Pentax $^{\circledR}$ EB-1970K and Fujinon ${ }^{\circledR}$ EB-530US). Transbronchial aspirations were performed through a 22-gauge needle (Cook Medical ${ }^{\circledR}$ EchoTip ${ }^{\circledR}$ Ultra Endobronchial HD Ultrasound Needle and Medi-Globe ${ }^{\circledR}$ SonoTip ${ }^{\circledR}$ EBUS Pro Needle). All procedures were done by the same physician with previous expertise for this method. According to the IASLC - International Association for the Study of Lung Cancer ${ }^{8}$ - a systematic evaluation of mediastinal stations was done, starting by placing the ultrasound probe on the left main bronchus and moving to the trachea, to study the following nodes: left pulmonary hilar (10 and 11L), left lower paratracheal (4L), subaortic (5), and upper left paratracheal $(2 \mathrm{~L})$. The right main bronchus was studied in a similar manner, moving to the trachea to examine the following nodes: right pulmonary hilar (10 and $11 \mathrm{R})$, lower right paratracheal (4R), and upper right paratracheal $(2 \mathrm{R})$. The subcarinal node (7) was evaluated through the main carina, on both sides. Last, an ultrasound study of the lung lesion was performed, placing the device as close as possible to it, according to the anatomical location.

All lesions found were characterized according to their location, size, echogenicity, and shape. Based on the ultrasound characteristics, potentially malignant lesions ${ }^{9}$ - round shape, a short axis greater than $8.3 \mathrm{~mm}$, and sharp margins - were selected for ultrasound-guided fine-needle aspiration. The needle was passed into different parts of the lesion, and the negative-pressure suction technique was used with a 20 $\mathrm{mL}$ syringe in all cases. In this study, a rapid onsite cytologic evaluation was not performed, but a minimum of 3 punctures per lesion was set. All material was collected into a flask containing $10 \%$ formalin and sent for pathologic analysis using the cellblock technique. All pathological analyses were done by the same physician with previous expertise for this method.

\section{Clinical follow-up}

All patients were followed-up for at least 12 months after the procedure. Data on clinical progression, 
complications, subsequent procedures and treatments performed were documented for analysis in this study. The following major complications were considered: excessive bleeding that was not self-limiting and that had evident clinical consequences and pneumo-thorax or mediastinitis. Adverse effects or allergic reactions to the medication used for sedation were considered anesthetic complications. Endoscopic findings such as immediate bleeding at the aspiration site, in small quantities, without hemodynamic repercussions and self-limiting, postprocedural coughing, and mild chest pain were considered inherent to the procedure and not classified as complications.

Patients with suspected lung cancer presenting negative results for malignancy by EBUS-TBNA were considered negative only after subsequent surgical confirmation (mediastinoscopy, thoracoscopy, or thoracotomy). Patients with suspected isolated mediastinal lymphadenopathy and suspected of having a benign reactional or inflammatory disease, with negative results by EBUS-TBNA, were considered negative in the absence of clinical or radiological worsening of the lesions in a clinical follow-up of at least 12 months after the procedure. The pathologist's interpretation of malignancy in the material obtained by EBUS-TBNA was considered sufficient and definitive for starting specific treatment.

\section{Statistical analysis}

The quantitative data were descriptively analyzed using summary measures, including the mean, median, minimum, maximum, and standard deviation $( \pm \mathrm{SD})$. Categorical variables are expressed as frequencies and percentages. A contingency table was used to calculate the following values: sensitivity, specificity, positive predictive value, negative predictive value, and accuracy, with their respective 95\% confidence intervals. The sample size (n) was calculated and estimated as 47 patients for a $95 \%$ confidence interval, considering a total error margin of $20 \%$ and an estimated proportion of 0.8571 . Statistical analyses were performed using Microsoft Excel ${ }^{\circledR}$ version 16.16.1.

\section{RESULTS}

A total of 55 patients were selected for the study. Of these, 3 patients were excluded from the sample for not undergoing aspiration: 1 patient for presenting vascular interposition in the needle's path, prohibiting safe access to the lesion; 1 patient due to normal extrinsic vascular compression findings (pulmonary artery ectasia); and 1 patient due to unsatisfactory clinical conditions (arrhythmia) for sedation, where the procedure was suspended by the anesthesia team.

The data for 52 remaining patients were thus included and analyzed in this study: mean age 61.5 \pm 11.7 (26-84), 29 females and 23 males. For the procedure indication, we found: 16 (30.7\%) patients with an isolated mediastinal lesion, and 36 patients (69.2\%) with suspected lung cancer. Among the 52 patients, a total of 221 lesions were found and characterized as shown in Table 1. The results of the patients' histopathological diagnoses by EBUS-TBNA are shown in Table 2.

Of the 52 subjects who underwent the procedure,

TABLE 1. CHARACTERIZATION OF THE LESIONS

\begin{tabular}{|c|c|}
\hline Total lesions found & $n=221$ \\
\hline Mean lesions per patient \pm SD (variation) & $4.25 \pm 2(1-8)$ \\
\hline Number of lesions selected for aspiration, n (\%) & $64(29 \%)$ \\
\hline Number of aspirations performed per lesion, n (\%) & $4.58 \pm 1.4(3-7)$ \\
\hline \multicolumn{2}{|l|}{ Lesion location } \\
\hline subcarinal (level 7), n (\%) & $38(17.2 \%)$ \\
\hline lower right paratracheal (level 4R), n (\%) & $34(15.4 \%)$ \\
\hline lower left paratracheal (level 4L), n (\%) & $26(11.8 \%)$ \\
\hline right hilar (level 10R), n (\%) & $23(10.4 \%)$ \\
\hline pulmonary parenchyma, n (\%) & $18(8.1 \%)$ \\
\hline right interlobar (level 11R), n (\%) & $17(7.7 \%)$ \\
\hline left hilar (level 10L), n (\%) & $17(7.7 \%)$ \\
\hline upper right paratracheal (level 2R), n (\%) & $16(7.2 \%)$ \\
\hline upper left paratracheal (level 2L), n (\%) & $12(5.4 \%)$ \\
\hline left interlobar (level 11L), n (\%) & $12(5.4 \%)$ \\
\hline subaortic (level 5), n (\%) & $4(1.8 \%)$ \\
\hline mediastinum (extensive involvement) & $4(1.8 \%)$ \\
\hline \multicolumn{2}{|l|}{ Lesion measurements } \\
\hline mean horizontal axis \pm SD (variation) & $17.2 \pm 13(5-80) \mathrm{mm}$ \\
\hline mean vertical axis \pm SD (variation) & $11.5 \pm 9.8(5-70) \mathrm{mm}$ \\
\hline
\end{tabular}

TABLE 2. HISTOLOGICAL DIAGNOSES BY EBUS-TBNA

\begin{tabular}{l|l}
\hline Negative for malignant neoplasia, $\mathrm{n}(\%)$ & $18(34.6 \%)$ \\
\hline Pulmonary adenocarcinoma, $\mathrm{n}(\%)$ & $17(32.7 \%)$ \\
\hline Pulmonary squamous cell carcinoma, $\mathrm{n}(\%)$ & $4(7.7 \%)$ \\
\hline Insufficient material, $\mathrm{n}(\%)$ & $3(5.8 \%)$ \\
\hline Pulmonary small cell carcinoma, $\mathrm{n}(\%)$ & $3(5.8 \%)$ \\
\hline Neuroendocrine carcinoma of the lung, $\mathrm{n}(\%)$ & $1(1.9 \%)$ \\
\hline Mediastinal metastasis of oropharyngeal carcinoma, $\mathrm{n}(\%)$ & $1(1.9 \%)$ \\
\hline Mediastinal metastasis of ovarian adenocarcinoma, $\mathrm{n}(\%)$ & $1(1.9 \%)$ \\
\hline Mediastinal metastasis of thyroid carcinoma, $\mathrm{n}(\%)$ & $1(1.9 \%)$ \\
\hline Mediastinal metastasis of breast carcinoma, $\mathrm{n}(\%)$ & $1(1.9 \%)$ \\
\hline Pulmonary metastasis of pleomorphic sarcoma, $\mathrm{n}(\%)$ & $1(1.9 \%)$ \\
\hline Mediastinal sarcoidosis, $\mathrm{n}(\%)$ & $1(1.9 \%)$ \\
\hline
\end{tabular}


22 (42.31\%) were diagnosed with locally advanced lung cancer in the mediastinum, of which 18 had a diagnosis of N2 lymph node involvement (13 pulmonary adenocarcinomas, 4 squamous cell (epidermoid) carcinomas, 1 neuroendocrine carcinoma) and 4 had a diagnosis of N3 lymph node involvement (4 pulmonary adenocarcinomas).

EBUS-TBNA confirmed the diagnosis of metastasis of other extrathoracic tumors in the mediastinum or lung in 5 patients (9.61\%), including 1 patient with metastatic oropharyngeal carcinoma in the upper right paratracheal mediastinal node (level 2R); 1 patient with metastatic breast carcinoma in the left hilar mediastinal node (level 1OL); 1 patient with metastatic thyroid carcinoma in the right hilar mediastinal node (level 10R); 1 patient with metastatic ovarian carcinoma in the subcarinal mediastinal node (level 7); and 1 patient with metastatic pleomorphic sarcoma in the lung parenchyma.

Furthermore, EBUS-TBNA confirmed the diagnosis of 3 patients (5.76\%) with small cell carcinoma of the lung parenchyma and $1(1.92 \%)$ patient with mediastinal sarcoidosis.

The examination diagnosed 18 patients (34.61\%) as negative for malignancy, as follows: 8 patients with initial suspicion of lung cancer - all confirmed negative by subsequent surgery; 2 patients with initial suspicion of lung cancer - diagnosed as squamous cell carcinoma by subsequent surgery; and 8 patients with initial suspicion of reactive/inflammatory isolated mediastinal lymph node enlargement without evidence of other pulmonary lesions - all followed-up for a minimum of 12 months without evidence of lesion progression by imaging methods and without clinical worsening.

The aspiration was insufficient in 3 patients (5.76\%), and all were referred for subsequent surgery, in which a diagnosis of lymphoma was established in 2 patients and of pulmonary adenocarcinoma in 1 patient.

The following statistical values were calculated: sensitivity $86 \%$ (74-97\% CI), specificity $100 \%$, positive predictive value $100 \%$, negative predictive value $77 \%$ (60-95\% CI) and accuracy 90\% (82-98\% CI). There were no major complications caused by the method used in this study.

\section{DISCUSSION}

In this study, data sets of 52 patients were analyzed to determine the overall efficacy of the method when applied to patients with lung and mediastinal lesions, regardless of the initial suspicion of malignant or benign disease. These results are consistent with those reported in other studies ${ }^{1,10}$, with high values for sensitivity - 86\% (CI 74-97\%), specificity - 100\%, positive predictive value - $100 \%$, negative predictive value - $77 \%$ (60-95\% CI), and accuracy - 90\% (82-98\% CI). There was also an agreement with these studies concerning the procedure's safety, as no major complications were observed.

Likewise, the literature shows excellent results for EBUS-TBNA when used for patients with suspected lung cancer and mediastinal metastasis. In a meta-analysis ${ }^{11}$ that included 1066 patients, the authors demonstrated that EBUS-TBNA can be considered a potential technique for the diagnosis and staging of patients with suspected lung cancer, with a sensitivity of $90 \%$, specificity of $99 \%$, positive predictive value of $99 \%$, negative predictive value of $93 \%$, and accuracy of $96 \%$. In another two meta-analyses ${ }^{12,13}$, the authors confirmed the excellent diagnostic performance of the method for mediastinal staging in patients with lung cancer, with a sensitivity of $88-93 \%$ and specificity of $100 \%$. Only 2 complications were reported (0.15\%).

In Brasil and in many developing countries, there is a high prevalence of infectious and inflammatory lung diseases, in particular tuberculosis and sarcoidosis. Furthermore, many individuals are exposed to environmental and occupational pollution and various physical and chemical agents without proper personal protective care, further increasing the possibility of lung or mediastinal lesions. In our study, 8 of 52 patients (16\%) were diagnosed with benign diseases, and, in one individual, histological confirmation of sarcoidosis was possible. Studies show that EBUSTBNA is efficient and safe for the investigation of patients with suspected mediastinal sarcoidosis and tuberculosis and that it has a diagnostic yield of over $80 \%^{2-5}$. Despite the high prevalence of tuberculosis in Brasil, in this study, we did not observe any patient diagnosed with this pathology by EBUS-TBNA. This may be explained by the fact that the patients were previously selected for the procedure and had no clinical, laboratory, or radiological signs of tuberculosis.

The diagnosis of lymphoproliferative disorders located in the mediastinum, including lymphoma, may be considered difficult to perform because it is necessary to collect biopsy macrofragments for adequate histopathological interpretation. In many cases, this diagnosis is only possible through surgical procedures 
and fine-needle aspiration, such as in EBUS-TBNA, is only capable of acquiring filamentary material. In this study, obtaining fragments by EBUS-TBNA for adequate histopathological interpretation was challenging, and 3 patients with material deemed insufficient were referred for surgery and diagnosed with mediastinal lymphoma. In a systematic review ${ }^{14}$ comprising patients with suspected mediastinal lymphoma, a large discrepancy was observed in the statistical results, with sensitivity ranging from $38-91 \%$. Moreover, subsequent invasive surgical procedures were necessary for $13-47 \%$ of patients. Based on our findings and those in the literature, we can infer a limitation of the method for diagnosing lymphomas, and additional surgical procedures may be often required to obtain a conclusive diagnosis by collecting macrobiopsy fragments or even by removing the whole lesion.

For many years, mediastinoscopy has been considered the gold standard for the mediastinal staging of lung cancer. However, it is a more invasive procedure with higher mortality than EBUS-TBNA. Studies show a similar yield for EBUS-TBNA and mediastinoscopy for the mediastinal staging of lung cancer (sensitivity of $84 \%$ versus $86 \%$, respectively) but with higher complication rates and lower false negative values for mediastinoscopy compared to
EBUS-TBNA ${ }^{15}$. Current recommendations indicate that EBUS-TBNA should be performed as the first procedure in suspected malignant mediastinal lesions, followed by mediastinoscopy in the case of negative results ${ }^{16}$. In our study, 5 patients had false-negative biopsy results by EBUS-TBNA - all of whom were referred for subsequent surgery - and were confirmed as having a malignancy. Based on these results, we obtained a negative predictive value of $77 \%$ - below the other statistical results but within the range observed in other studies $(67 \%-97 \%)^{15}$. Unlike these studies, which included only patients with suspected lung cancer, our study evaluated all individuals in a single group, including patients with suspected mediastinal lymphoma, in which EBUSTBNA has limitations, which may explain this result.

Different studies have shown the important role of EBUS-TBNA in reducing the rate of subsequent surgical procedures necessary for diagnosing pulmonary and mediastinal lesions. In a prospective study ${ }^{17}$ that included 105 patients who underwent EBUS-TBNA for lung cancer staging, it was found that the method avoided the need to perform 50 subsequent invasive procedures (29 mediastinoscopies, 8 thoracotomies, 4 thoracoscopies, and 9 CT-guided chest aspirations), concluding that EBUS-TBNA can have a large impact

FIGURE 1. CLINICAL COURSE OF PATIENTS SUBMITTED TO EBUS-TBNA.

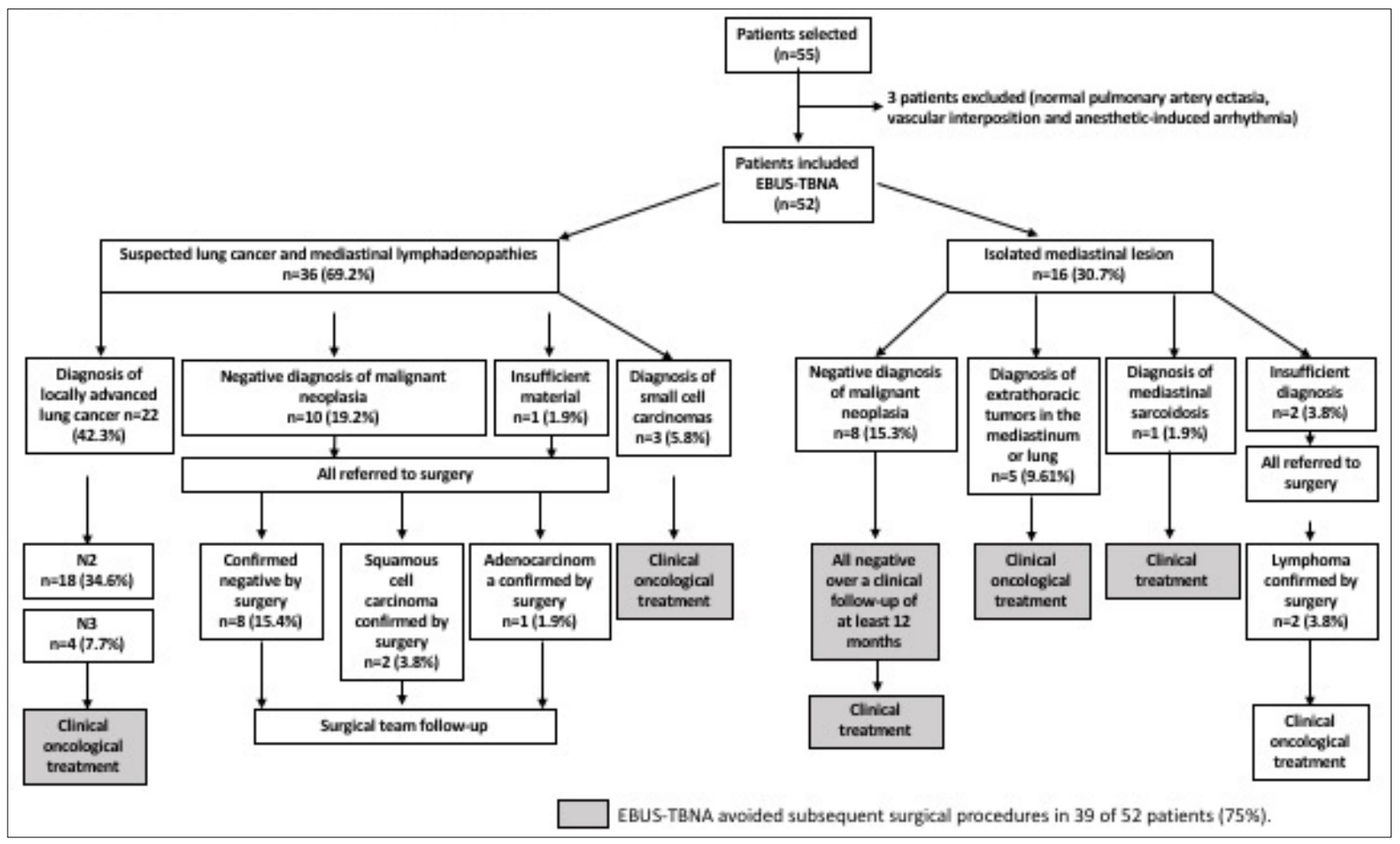


on patient management. In another study with 215 patients ${ }^{18}$, the authors demonstrated that when applied to benign and malignant thoracic injuries, EBUS-TBNA was able to avoid performing 104 subsequent invasive surgical procedures and 32 hospitalizations. In another prospective and randomized study ${ }^{19}$, the authors evaluated the clinical efficiency and cost-effectiveness of endoscopic ultrasound compared to standard surgical staging alone in patients with lung cancer who were potential candidates for curative surgery. The authors observed a higher rate of unnecessary thoracotomies when the staging was performed by conventional surgical methods compared to endoscopic ultrasound (18\% vs. $7 \%$, respectively). Furthermore, the study concluded that the ultrasound staging method is more tolerable and more cost-effective than surgical staging alone.

In our study, EBUS-TBNA avoided other subsequent surgical procedures in 39 of 52 patients (75\%). A total of 30 patients were sent directly for specific cancer treatment, with 22 diagnosed with locally advanced disease (N2 or N3 lymph node involvement), 5 diagnosed with metastases from other extrathoracic tumors, and 3 diagnosed with small cell carcinoma. In addition, 9 patients were referred for non-oncological clinical treatment, with 1 patient diagnosed with mediastinal sarcoidosis, and 8 diagnosed with reactionary/inflammatory mediastinal lymphadenopathies (Figure 1).

\section{CONCLUSION}

EBUS-TBNA is a safe, effective, and valuable method. This technique can significantly reduce the rate of subsequent surgical procedures required for the diagnosis of lung and mediastinal lesions.

\section{Author's Contribution}

Concept and study design: AC, RS. Data acquisition: AC, LC, FM, MC. Data analysis/interpretation: MS, FB. Statistical analysis: AC. Supervision or mentorship: LC, FM, MB, VD, RS. Manuscript writing: AC. All authors participated in the approval of the final version of the manuscript.

\section{Competing interests}

None for all authors.

\section{RESUMO}

OBJETIVO: Avaliar a importância da ecoendoscopia endobrônquica com punção por agulha fina (Ebus-TBNA) no diagnóstico das lesões pulmonares e mediastinais.

MÉTODOs: Estudo prospectivo e do tipo coorte, no qual foram incluídos 52 pacientes, durante o período de dois anos (2016 a 2018), submetidos ao procedimento de Ebus-TBNA.

RESULTADOS: Do total de 52 indivíduos submetidos ao procedimento, 22 (42,31\%) pacientes foram diagnosticados com neoplasia pulmonar localmente avançada (N2 ou N3). O método confirmou o diagnóstico de metástases de outros tumores extratorácicos no mediastino ou pulmão em cinco pacientes (9,61\%), três pacientes (5,76\%) com carcinoma de pequenas células, um paciente (1,92\%) com sarcoidose, oito pacientes (15,38\%) com linfonodomegalias reacionais/inflamatórias e resultado insuficiente em três pacientes (5,76\%). O EbusTBNA evitou a realização de outros procedimentos cirúrgicos subsequentes em 39 de 52 (75\%) pacientes. Foram calculados os valores de sensibilidade de $86 \%$, especificidade de $100 \%$, valor preditivo positivo de $100 \%$, valor preditivo negativo de $77 \%$ e acurácia de $90 \%$. Não foram observadas complicações maiores pelo método neste estudo.

CONCLUSÃO: O Ebus-TBNA é um método seguro, eficaz e de relevante importância. Este exame pode reduzir significativamente o número de procedimentos invasivos subsequentes necessários para o diagnóstico das lesões pulmonares e mediastinais.

PALAVRAS-CHAVE: Neoplasias pulmonares. Linfonodos. Biópsia por agulha/métodos. Doenças do mediastino/diagnóstico. Aspiração por agulha fina guiada por ultrassom endoscópica. Biópsia guiada por imagem.

\section{REFERENCES}

1. Chandra S, Nehra M, Agarwal D, Mohan A. Diagnostic accuracy of endobronchial ultrasound-guided transbronchial needle biopsy in mediastinal lymphadenopathy: a systematic review and meta-analysis. Respir Care. 2012;57(3):384-91.

2. Agarwal R, Srinivasan A, Aggarwal AN, Gupta D. Efficacy and safety of convex probe EBUS-TBNA in sarcoidosis: a systematic review and meta-analysis. Respir Med. 2012;106(6):883-92.
3. Trisolini R, Lazzari Agli L, Tinelli C, De Silvestri A, Scotti V, Patelli M. Endobronchial ultrasound-guided transbronchial needle aspiration for diagnosis of sarcoidosis in clinically unselected study populations. Respirology. 2015;20(2):226-34

4. Ye W, Zhang R, Xu X, Liu Y, Ying K. Diagnostic efficacy and safety of endobronchial ultrasound-guided transbronchial needle aspiration in intrathoracic tuberculosis: a meta-analysis. J Ultrasound Med. 2015;34(9):1645-50. 
5. Li W, Zhang T, Chen Y, Liu C, Peng W. Diagnostic value of convex probe endobronchial ultrasound-guided transbronchial needle aspiration in mediastinal tuberculous lymphadenitis: a systematic review and meta-analysis. Med Sci Monit. 2015;21:2064-72.

6. Senturk A, Babaoglu E, Kilic H, Hezer H, Dogan HT, Hasanoglu HC, et al. Endobronchial ultrasound-guided transbronchial needle aspiration in the diagnosis of lymphoma. Asian Pac J Cancer Prev. 2014;15(10):4169-73.

7. Carbonari A, Camunha M, Binato M, Saieg M, Marioni F, Rossini L. A rare case of mediastinal metastasis of ovarian carcinoma diagnosed by endobronchial ultrasound-guided transbronchial needle aspiration (EBUSTBNA). J Thorac Dis. 2015;7(10):E505-8.

8. Rusch VW, Asamura H, Watanabe H, Giroux D|, Rami-Porta R, Goldstraw P; Members of IASLC Staging Committee. The IASLC lung cancer staging project: a proposal for a new international lymph node map in the forthcoming seventh edition of the TNM classification for lung cancer. J Thorac Oncol. 2009;4(5):568-77.

9. Gill KR, Ghabril MS, Jamil LH, Hasan MK, McNeil RB, Woodward TA, et al. Endosonographic features predictive of malignancy in mediastinal lymph nodes in patients with lung cancer. Gastrointest Endosc. 2010;72(2):265-71

10. Gahlot T, Parakh U, Verma K, Bhalotra B, Jain N. Endobronchial ultrasound-guided transbronchial needle aspiration in diagnosing mediastinal lymphadenopathy. Lung India. 2017;34(3):241-6.

11. Dong X, Qiu X, Liu Q, Jia J. Endobronchial ultrasound-guided transbronchial needle aspiration in the mediastinal staging of non-small cell lung cancer: a meta-analysis. Ann Thorac Surg. 2013;96(4):1502-7.

12. Gu $P$, Zhao $Y Z$, jiang LY, Zhang $W$, Xin $Y$, Han BH. Endobronchial ultrasound-guided transbronchial needle aspiration for staging of lung cancer: a systematic review and meta-analysis. Eur J Cancer. 2009;45(8):1389-96.

13. Adams K, Shah PL, Edmonds L, Lim E. Test performance of endobronchial ultrasound and transbronchial needle aspiration biopsy for mediastinal staging in patients with lung cancer: systematic review and meta-analysis. Thorax. 2009;64(9):757-62.

14. Kheir F, Itani A, Assasa $O$, Alraiyes AH. The utility of endobronchial ultrasound-transbronchial needle aspiration in lymphoma. Endosc Ultrasound. 2016;5(1):43-8

15. Ge X, Guan W, Han F, Guo X, lin Z. Comparison of endobronchial ultrasound-guided fine needle aspiration and video-assisted mediastinoscopy for mediastinal staging of lung cancer. Lung. 2015;193(5):757-66.

16. Sehgal IS, Dhooria S, Aggarwal AN, Behera D, Agarwal R. Endosonography versus mediastinoscopy in mediastinal staging of lung cancer: systematic review and meta-analysis. Ann Thorac Surg. 2016;102(5):1747-55.

17. Yasufuku K, Chiyo M, Koh E, Moriya Y, lyoda A, Sekine Y, et al. Endobronchial ultrasound-guided transbronchial needle aspiration for staging of lung cancer. Lung Cancer. 2005;50(3):347-54.

18. Steinfort DP, Hew MI, Irving LB. Bronchoscopic evaluation of the mediastinum using endobronchial ultrasound: a description of the first 216 cases carried out at an Australian tertiary hospital. Intern Med J. 2011:41(12):815-24.

19. Sharples LD, Jackson C, Wheaton $E$, Griffith $G$, Annema IT, Dooms $C$, et al Clinical effectiveness and cost-effectiveness of endobronchial and endoscopic ultrasound relative to surgical staging in potentially resectable lung cancer: results from the ASTER randomized controlled trial. Health Technol Assess. 2012;16(18):1-75, iii-iv.

Regarding the article "VALUE OF ENDOBRONCHIAL ULTRASOUND-GUIDED TRANSBRONCHIAL NEEDLE ASPIRATION (EBUS-TBNA) IN THE DIAGNOSIS OF LUNG AND MEDIASTINAL LESIONS" with DOI number: https://dx.doi.org/10.1590/1806-9282.66.9.1210, published in Journal of the Brazilian Medical Association, 2020;66(9), page 1210, changed:

From: Hospital Santa Casa de São Paulo - Departamento de Cirurgia Toráxica, São Paulo, SP, Brasil To: Hospital Santa Casa de São Paulo - Departamento de Cirurgia Torácica, São Paulo, SP, Brasil.

From: Inclusion criteria

Patients who had normal anatomical findings or vascular interposition that did not indicate nor allowed needle aspiration.

To: Patients who had normal anatomical findings or vascular interposition that did not indicate nor allowed needle aspiration.

From: The following major complications were considered: excessive bleeding that was not self-limiting and that had evident clinical consequences and lung, pneumo-thorax, or pneumomediastinum infections.

To: The following major complications were considered: excessive bleeding that was not self-limiting and that had evident clinical consequences and pneumo-thorax or mediastinitis. 